\title{
O TRABALHO DIDÁTICO E SUA FORMA HISTÓRICA NAS COMUNIDADES PRIMITIVAS
}

Jander Fernandes Martins ${ }^{1}$

\section{RESUMO}

O presente artigo tem por objetivo apresentar os resultados obtidos na pesquisa final do Trabalho de Conclusão de Curso em Pedagogia - Licenciatura Plena (Diurno) pela Universidade Federal de Santa Maria /RS a qual, teve como objetivo "analisar e identificar as formas históricas de educadores nas civilizações antigas à luz da Organização do Trabalho Didático". Sendo aqui apresentada a análise e resultado referente ao "Modo de Produção Primitivo". Para compreender a primeira forma histórica de educador, partiu-se da seguinte questão: Qual foi a primeira forma histórica de educador responsável pelo Trabalho Didático no Modo de Produção Primitivo? Metodologicamente, elegeu-se a Ciência da História, tendo como categoria analítica a Organização do Trabalho Didático (OTD) como método, utilizando como recurso a "pesquisa bibliográfica" em manuais de história da educação sendo este procedimento executado em caráter "exploratório". Os resultados aqui socializados justificam-se, pois são reveladores, pois, acredita-se que nas comunidades primitivas a forma histórica de relação educativa deu-se já em caráter de "preceptorado"; sendo a primeira forma desenvolvida de educador, o que designamos de "ágrafo-bardo"; quanto ao instrumental mediador acredita-se ter sido a "linguagem" o instrumental didático. Quanto ao local específico, eram utilizados desde simples passeio às florestas e bosques, caça, pesca, coleta e plantio como também os rituais de iniciação no interior da comunidade. Assim, a relevância deste estudo com vistas a estabelecer um marco inicial desta forma histórica de relação educativa, a partir dos pressupostos conceituais aqui elegidos é de suma importância para a História da Educação, da Pedagogia e áreas afim como Antropologia, Sociologia e a História.

Palavras-Chave: Organização do Trabalho Didático; Trabalho Docente; História da Educação; História da Pedagogia.

\section{THE DIDACTIC WORK AND ITS HISTORICAL FORM IN PRIMITIVE COMMUNITIES}

\begin{abstract}
This article aims to present the results obtained in the research end of completion of course work in education-Full Degree (daytime) at the Federal University of Santa Maria/RS which aimed to "analyze and identify the historical forms of educators in ancient civilizations in the light of the Didactic Work of the Organization". Being presented here, the analysis and result for the "Primitive Mode of Production". To understand the first historical form of educator broke the following question: what was the first historical form of educator responsible for Educational Work in the Primitive mode of production? Methodologically, elected to the Science of History, with the analytical category "Didactic Work of the Organization", as method using as the "bibliographical research" in manuals of history of education being this procedure performed in character "exploratory". The results here are justified because socialized are developers, because it is believed that in primitive communities the historical form of educational relationship took place already in character "Preceptorship"; being the first form developed an educator, what we call "agrafo-Bard"; as for the instrumental mediator is believed to have been the "language" the didactic instrumental. As for the specific location, were used from simple walk to forests and Woods, hunting, fishing,
\end{abstract}


collecting and planting as well as the rites of initiation within the community. Thus, the relevance of this study to establish a starting point of this historical form of the educational relationship, from the conceptual assumptions here elected is of paramount importance for the history of education, pedagogy and related areas as anthropology, Sociology and history. Keywords: Didactic Work of the Organization; Teaching Work; History of Education; History of Pedagogy.

\section{Introdução}

O presente trabalho versa sobre alguns dos resultados obtidos na pesquisa do Trabalho de Conclusão de Curso (TCC) em Pedagogia - Licenciatura Plena (diurno) pela Universidade Federal de Santa Maria /RS (UFSM) o qual, por sua vez, teve como objetivo "analisar e identificar as formas históricas de educadores nas civilizações antigas à luz da Organização do Trabalho Didático", tendo como objeto de pesquisa, as comunidades primitivas e as civilizações: egípcia e mesopotâmica.

Tal empreendimento teórico surgiu de paulatinos e densos estudos os quais tinham como foco o trabalho docente, em especial, a sua constituição histórica. A partir disto, constatou-se que, grande parte dessas produções e pesquisas acadêmicas, não tem como objeto de estudo a "constituição histórica" deste "trabalho/ofício/ato/emprego", O que permitiu identificar duas categorias de autores que abordam esta temática:

a. Autores, como Cação (2001), Lancillotti (2008), Saviani (1997), Wenzel (1994), Kuenzer (2005) discutem o tema relacionando-o à intensificação da jornada de trabalho, fragmentação, precarização, desvalorização social $e$ econômica, proletarização, feminização, simplificação, função;

b. Outros autores, como Libâneo (1998), Pimenta e Ghedin (2008), Perrenoud (2000), Veiga, Araujo e Kapuziniak (2005), Veiga e d'Ávila (2008), Ludke e Boing (2004) estudam o trabalho docente em análises de curtos eventos, priorizando a construção de um perfil, tais como: ser reflexivo, competente $e$ pesquisador.

Naquele projeto, optou-se por analisar os educadores de diferentes períodos, correspondendo, sempre, a seu contexto histórico, "o que envolveria um exame dos condicionantes sociais, econômicos, políticos e culturais na sua evolução ao longo do tempo" (SAVIANI, 2008, p. 387). Sendo aqui apresentada a análise e resultado referentes ao "Modo de Produção Primitivo".

Para compreender a primeira forma histórica de educador, estabeleceu-se a seguinte questão: Qual foi a primeira forma histórica de educador responsável pelo Trabalho Didático no Modo de Produção Primitivo?

\section{Aportes Teórico-Metodológicos}

Para o desdobramento teórico-metodológico, elegeu-se como categoria Organização do Trabalho Didático ${ }^{3}(O T D)$ pressuposto assentado à luz da Ciência da História ${ }^{4}$, portanto, marxiana. Logo, "constitui-se, conceitualmente, nos limites de outras categorias mais centrais, tais como trabalho e organização técnica do trabalho, e as implica" (ALVES, 2005 , p. 10, grifos nossos). O que para o presente estudo, considerou-se ousado e relevante, visto que, compreender no limiar das civilizações primitivas, sua forma histórica de organização em comunidade e, no interior, desta estrutura identificar uma provável forma histórica de educador, torna a análise e o estudo relevante. 
Como assinalado, esta categoria organiza-se em acordo com as condições históricas dadas, ou seja, materiais. Neste sentido, o autor esclarece sobre algumas das formas históricas de relação educativa:

\begin{abstract}
na Antiguidade e na Idade Média o educador era o preceptor; na Idade Moderna surgiu o professor, dominante até nossos dias [...] nas duas épocas referidas, os estudantes assumiram formas, respectivamente, de discípulos e de alunos organizados em classe. (ALVES, 2005, p. 11, grifos nossos)
\end{abstract}

Assim, é detendo-se um pouco mais sobre esta primeira forma histórica de Trabalho Didático, "o preceptorado" o qual, caracterizava-se por ser uma relação educativa predominantemente individualizada, é que o presente trabalho empreendeu seus esforços.

Quanto à "abordagem da pesquisa", buscou-se tomar como base norteadora de reflexão, a concepção do Materialismo Histórico (MARX \& ENGELS, 2005; MARX, 2008). Concepção esta a qual, acredita-se estar em acordo e coerente com os objetivos gerais da pesquisa as quais almejavam produzir uma constituição "formas históricas de educadores". Esta, no sentido apresentado por Bottomore (2001, pp. 259-260) "expressão que designa o corpo central de doutrina da concepção materialista da historia, núcleo cientifico e social da teoria marxista".

Logo, pensa-se que, tal empreendimento ganha sustentação (teórica e conceitual), a partir do momento em que, concebe-se o fato de que "cada época, concretamente, produz a relação educativa que lhe é peculiar. Isto é, produz uma forma histórica de educador" (ALVES, 2005, p. 11, grifos nossos), ou seja, se cada época produz suas formas históricas de relações sociais concretas, pode-se então pressupor a possibilidade de se analisar as diferentes formas históricas de educadores. Neste caso, a primeira forma histórica de educadores nos primórdios da história.

Para isso, preferiu-se fazer uso da "pesquisa bibliográfica" em manuais de história da educação sendo este procedimento metodológico executado em caráter "exploratório" (GIL, 2008) o que por sua vez, proporcionou ao método de pesquisa um "caráter aproximativo historiográfico" em "fontes secundárias".

Assim, a "coleta de dados" realizou-se em termos de consulta "bibliográfica", visto que a

[...] pesquisa bibliográfica é desenvolvida a partir de material já elaborado, constituído principalmente de livros e artigos científicos. Embora em quase todos os estudos seja exigido algum tipo de trabalho desta natureza, há pesquisas desenvolvidas exclusivamente a partir de fontes bibliográficas [...] (GIL, 2008, p. 50)

Decidiu-se que esta técnica de levantamento de dados era a mais adequada ao objetivo que aqui se propõe, pois, permitiu "[...] a cobertura de uma gama de fenômenos muito mais ampla do que aquela que poderia pesquisar diretamente" (GIL, 2008, p. 27, grifos nosso), principalmente, em se tratando de uma pesquisa na qual o estudo histórico é necessário, já que "a pesquisa bibliográfica também é indispensável nos estudos históricos" (GIL, 2008, p. 27, grifos nosso).

Quanto à periodização, utilizou-se a referência a "Contextos Históricos", enquanto uma questão técnica, conforme escreve Saviani (2008, p. 12):

A questão da periodização é, sem dúvida, uma das mais relevantes e também das mais complexas [...] Em verdade, a periodização não é um dado empírico [...] A periodização, enquanto uma exigência de compreensão do objeto, é, antes, uma 
questão de teórica que se põe para o historiador ao enfrentar a tarefa de organizar os dados visando a explicar o fenômeno que se propôs investigar.

Deste modo, para investigar a primeira forma histórica de educador, em seu "contexto histórico", no interior de um "Modo de Produção Primitivo". Prevaleceu o entendimento de "Formações Socioculturais" que K. Marx, em Formações Econômicas PréCapitalistas (1986) dá a expressão "Formações Econômico-Sociais". E o entendimento de "Processo Civilizatório" adotado por Darcy Ribeiro (1987).

Deste modo, a aproximação realizada entre uma concepção marxiana com esta última, antropológica, nos pareceu cabível, visto que, no que diz respeito a esta última,

$\mathrm{O}$ conceito de processo civilizatório permite essa abordagem conjunta porque ressalta, na sua acepção global, a apreciação dos fenômenos de desenvolvimento progressivo da cultura humana tendentes a homogeneizar configurações culturais. E valoriza, na sua acepção limitada, os fatores de diferenciação das culturas singulares, só explicáveis como esforços de adaptação a condições ecológicas e históricas específicas e como produto de uma criatividade própria, capaz de apresentar respostas alternativas aos mesmos incitamentos básicos. (RIBEIRO, 1987, p. 41)

Visto que esta categoria tanto em suas duas (2) acepções permite compreender em um determinado grupo social os seus aspectos culturais, econômicos, políticos, sociais, em uma palavra, compreender os seus condicionantes materiais vão de encontro com as premissas de análise das bases produtivas de uma dada sociedade conforme entendimento em "Formações Socioculturais", de Karl Marx, no sentido mais aproximado de socioeconômico, evidentemente.

Assim, na tentativa de melhor compreender e esmiuçar estes "esquemas conceituais", o Modo de Produção/Formação Socioeconômico/Formações Socioculturais/Processo Civilizatório. Nos leva a problematizar a questão do "conceito de estágio" 5 .

Portanto, para analisar e identificar a primeira forma histórica de educadores a realizarem o trabalho didático em um determinado contexto histórico no interior de um Modo de Produção específico, o Primitivo, elegeu-se as categorias "Organização do Trabalho Didático, Formações socioculturais e Processos Civilizatório" (ALVES, 2005; ENGELS, 2010; MARX, 1985; MARX \& ENGELS, 2005; RIBEIRO, 1985).

\section{A Relação de Produção Tribal De K. Marx, O Estágio de Selvageria de F. Engels e as Sociedades Arcaicas de D. Ribeiro.}

Primeiramente, partiremos das premissas de Marx e Engels n'a Ideologia Alemã, seguido de A Origem da Família, Propriedade Privada e Estado e O papel do trabalho na transformação do macaco em homem de F. Engels, logo depois, as Formações de Marx, e por fim, Os Processos Civilizatórios de Ribeiro.

Em A Ideologia Alemã, Marx e Engels (2005, p. 46) ao definirem que "os diferentes estágios de desenvolvimento da divisão do trabalho" tem como primeira forma histórica de propriedade a "Stammeigentum", ou seja, a "propriedade tribal". Logo, o que se percebe nessa perspectiva do materialismo histórico é que cada forma histórica de divisão do trabalho apresenta uma correspondente forma de propriedade, em nosso caso, a tribal/primitiva. "ela corresponde ao estágio não desenvolvido da produção, em que um 
povo se alimenta de caça e pesca, da criação de gado ou, no máximo, da agricultura [...] a divisão do trabalho está ainda pouco desenvolvida e se limita a uma maior extensão da divisão natural no seio da família." (MARX \& ENGELS, 2005, p.46) Ou seja, trata-se de uma organização de caráter natural, limitada a divisão sexual no interior de pequenos grupos de parentescos tribais.

Não muito longe disto, Engels também apresenta sua contribuição a essa forma de propriedade tribal/primitiva em dois manuscritos que aqui se explicita alguns fragmentos pertinentes, "O papel do trabalho na transformação do macaco em homem" e "A Origem da Família, da Propriedade e do Estado". Naquele manuscrito, sua contribuição está nas argumentações sobre como "as manadas de macacos foram gradativamente transformandose em homens" através de sucessivos passos de transformação e interação com a natureza, inicialmente pelo e com o trabalho, em seguida, com a linguagem articulada, a habitação, a alimentação, o uso de instrumentos, entre outras descobertas. Já na segunda obra, o autor discorre com maior envergadura e amplitude sobre o tema, visto que discorre sobre "os estágios de desenvolvimento do homem" a partir dos estudos de Lewis Morgan, logo, em nosso entendimento, trata-se de uma produção mais fecundas sobre o tema, objeto do presente trabalho. Dentre as periodizações sistematizadas por F. Engels, o "Estágio Selvagem" é o que interessa aqui, para o autor, subdividia-se em 3 (três) fases (inferior, médio e superior) ${ }^{6}$.

Já Darcy Ribeiro, em Processos... (1985), em linhas gerais, pondera o fato de que ao estudar "Sociedades Arcaicas", é preciso levar em consideração duas dimensões, a saber: a) "processos civilizatórios gerais", dimensão esta que permite visualizar, principalmente, as alterações nos sistemas adaptativos, associativo e ideológico decorrentes do impacto das revoluções tecnológicas sobre as sociedades (RIBEIRO, 1985, p. 54, grifos nossos; b) já os "processos civilizatórios específicos", permitem "identificar as expansões de tradições culturais singulares associadas a movimentos econômicos e políticos de dominação que se cristalizam em civilizações individualizadas" (IDEM, p. 55, grifos nossos).

Assim, tem-se que para o mesmo "contexto e período histórico", Karl Marx denomina como "comunidade primitiva"; F. Engels denominou como "comunismo primitivo ou estágio de selvageria" e D. Ribeiro identifica como "tribos de caçadores e coletores" as Sociedades Arcaicas. Para a mesma organização social, a saber, o Modo de Produção Primitivo.

\section{Os Manuais De História da Educação e a Questão da Periodização.}

Realizada a constatação e aproximação conceitual referente à questão de "contexto histórico" e "periodização", chega-se aos os manuais de história da educação, "objetos de análise" no processo de identificação de "quais foram às formas históricas de educadores" no contexto histórico supracitados.

As obras que nos serviram de instrumento de manipulação, análise e extrações das informações, foram escolhidas a priori e são as seguintes: Alves (2005); Aranha (2006); Cambi (2010); Giordani (1972); Giles (1987); Havelock (s/d; 1996); Larroyo (1974); Luzuriaga (1990); Manacorda (2000); Marrou (1975); Monroe (1976); Mialaret \& Vial (s/d); Ponce (2007). 
As fontes consultadas e manuseadas nesta pesquisa quase que em sua totalidade estão assentadas sobre uma "tradicional divisão cronológica da história" (GIORDANI, 1972, p. 15). Isto se dá pelo fato de que, até o séc. XVII esta "periodização", conhecida como "tripartição" da história, referia-se à "Antiguidade, Idade Média e Época Moderna" (idem). Divisão esta que remonta aos humanistas (idem.). Mais especificamente, à Keller (em latim, Cellarius) que consagrou esta tripartição com a publicação de sua obra "História Tripartida" em 1688. "Para Cellarius, a história Antiga chegava até Constantino, a Média até a tomada de Constantinopla pelos turcos, e a Moderna, até os dias em que vivia". Sendo que, apenas no séc. XIX acrescentou-se a esta tradicional divisão as expressões "Pré-história e Idade Contemporânea" (idem).

Tal sistematização convencionada também foi enriquecida com outras unidades de periodização, como destaca Fernandes (2010, p. 15, nota de rodapé 6, grifos nossos):

\begin{abstract}
Convencionou-se dividir a história da seguinte forma: 1) Pré-Histórica (período que se estende do surgimento da humanidade até o aparecimento da escrita, por volta do ano de 4.000 a. C.; 2) Idade Antiga (que se inicia com a invenção da escrita e se prolonga até a queda do Império Romano, no ano de 476 d. C.); 3) Idade Média (que se estende até a tomada da cidade de Constantinopla pelos turcos em 1453 d. C.); 4) Idade Moderna (que vai da queda de Constantinopla até a Revolução Francesa, em 1789) e, 5) Idade Contemporânea que, por sua vez, vai da Revolução Francesa até nossos dias. Esta divisão precisa ser entendida no seu caráter pedagógico, pois, estes estágios da história estão intimamente relacionados, articulados entre si, de modo que é impossível a compreensão do homem atual sem se levar em apreço que ele é um produto de todo acúmulo histórico.
\end{abstract}

Embora as divisões utilizadas nos diversos estudos sobre a História assentem-se, independentemente das perspectivas utilizadas como referencial teórico-metodológico, em uma "periodização" cronológica baseada nesta organização de Cellarius, ainda que atualmente, acrescentem-se as épocas denominadas como "proto e pré-história", por exemplo, se tratam de divisões, como sugere Larroyo (1974, p. 27), "demasiado ampla e geral", o que por sua vez, impede de se penetrar nas "formações particulares do passado pedagógico" (IDEM), pois, ela não nos permitiria identificar uma forma histórica concreta de educador, por exemplo, como é o caso do presente trabalho.

Levando em consideração essa característica, identificada nos materiais analisados, a qual poderia comprometer o trabalho, é que se justifica também a base teórico-metodológica supracitada. Mais do que isso, tal característica vai de encontro com o entendimento da História enquanto "sucessão de fatos lineares, organizados cronologicamente de tal forma que um fato sucede o outro" 7 ".

Exemplo concreto de superação desses condicionantes, os quais caracterizam esses manuais de história têm-se o exemplo na Antiguidade a qual, tradicionalmente, é tomada como referência a história dos gregos, os romanos, os egípcios, os hebreus e os mesopotâmicos. Entretanto, na perspectiva aqui adotada, levanta-se uma questão fundamental, qual seja: “[...] mas os celtas, os germanos e os eslavos não possuem também a sua própria Antiguidade?” (BEER, 2006, p. 13). Tal indagação, a partir do entendimento aqui percorrido não fica sem resposta:

Os antigos hebreus, os helenos e os romanos tiveram igualmente a sua Antiguidade, a sua Idade Média e os seus tempos Modernos. Apenas surgiram mais cedo na cena histórica do que os germanos e eslavos, por exemplo. Mas também atravessaram esses períodos, criando determinadas instituições e ideias, que sempre correspondem, aproximadamente, a tais períodos. (IDEM, p. 14, grifos nossos) 
Isto é, embora civilizações representantes de um mesmo "Modo de Produção", o escravista, desenvolveram-se distintamente umas das outras, enquanto formações socioculturais, evidenciando que o desenvolvimento histórico de uma dada organização social/sociedade/civilização/comunidade se dá em termos dialéticos.

Outra situação concreta pode ser verificada "na vida intelectual dos romanos e germanos, nos séc. XV e XVI, tem muitos pontos de contato com a vida intelectual dos gregos, no século VI a. C" (IDEM, IBIDEM). Como se explica esse fenômeno? Tal acontecimento explica-se devido ao fato de que, naquela época "os gregos já haviam deixado para trás a sua Antiguidade e a sua Idade Média, já viviam nos seus Tempos Modernos. Criavam, portanto, produtos intelectuais correspondentes a essa época da sua história". (IDEM, IBIDEM).

Ora, captando em sua totalidade esses condicionantes materiais, acima citados, e transpondo-os para o plano das três (3) categorias basilares deste trabalho, têm-se, enquanto exemplificação, que suas formas históricas de educadores também eram distintas: enquanto os eslavos e germanos tinham os "bardos" como forma histórica de educador (em séc. VI a. C), os gregos haviam produzido e inaugurado, a "tradição pedagógica" (CAMBI, 1999), com seus "sofistas e filósofos", enquanto àqueles utilizavam a "epopeia e a poesia cantarolada" para educar seu povo iletrado, estes últimos já educavam seus jovens através da escrita alfabética, da retórica, da filosofia, da matemática, da dialética. Em contrapartida, esta forma histórica de educadores produzidos entre eslavos e germanos, havia surgido na Grécia Homérica centenas de anos antes. Fenômeno este, evidenciado somente se levado em consideração estas três categorias em processo de sinergia como é o caso aqui proposto. (BEER, 2006; ENGELS, 2010; HAVELOCK, 1996; s/d; MARX, 1986; MARX \& ENGELS, 2005; PONCE, 2007; RIBEIRO, 1985)

\section{A Primeira Forma Histórica de Educador no Trabalho Didático.}

Até o presente momento, tentou-se explicitar, a partir do esquema conceitual supracitado, como se poderia identificar uma possível forma histórica de Trabalho Didático realizado por um tipo específico de educadores.

Intentado isso, partiu-se para algumas exemplificações concretas específicas do estágio civilizatório, a saber, "Sociedades Arcaicas" (RIBEIRO, 1985), "Fase Superior do Estágio de Barbárie" (ENGELS, 2010), produtivamente, "inicia-se com a fundição do minério de ferro, e passa à fase da civilização com a invenção da escrita alfabética e seu emprego para registros literários" (ENGELS, 2010, p. 42). A este período, podem-se compreender os "povos gregos da época heroica" (IDEM, IBIDEM). Para Engels (IDEM, p. 43) nos "poemas homéricos, principalmente na Ilíada, encontramos a época mais florescente" deste estágio de desenvolvimento. Assim, no limiar da fase Superior da Barbárie, as forças produtivas dos povos, principalmente os europeus, ainda iniciavam o seu processo de transição de um Modo de Produção Primitivo (MARX, 1986) para um Estágio de Civilização (ENGELS, 2010) ou Arcaico (RIBEIRO, 1985).

É, justamente neste contexto histórico, "período de transição", que surge a primeira forma histórica de educadores: "os ágrafos-bardos, xamãs, anciões ou gurus"; no limiar do período da invenção da escrita alfabética (MAN, 2002), a qual se considerou como sendo a "Primeira Revolução Pedagógica". Visto assim, é nesta primeira fase da "civilização, das formações de cidades-estados, etc." que se pode ter uma descrição aproximativa e de 
registros sobre essas "sociedades primevas" (LEACOCK, 2010). Um exemplo desse movimento de captação, dentre os manuais pesquisados, é o de Gusdorf (1970, p. 270, grifos nossos):

[...] depositário das tradições sagradas, mestre dos rituais de iniciação, o xamane, feiticeiro, homem-medicina é o primeiro de todos os mestres-escolas do gênero humano $[\ldots]$ a sua função consiste em assegurar a continuidade da vida social pela transmissão dos segredos que subtendem e inspiram [...]

Isto é, essas sociedades primevas que, organizadas de forma tribal à base de coleta e a caça tinham já em sua divisão social do trabalho, os "xamanes, feiticeiros, etc." como guardiões da sua cultura com a "função" e responsabilidade de assegurar, preservar e transmitir todo o legado cultural e histórico produzido socialmente no interior dessas comunidades primitivas.

Esta "continuidade" tinha um momento oportuno de se materializar, enquanto gênese do trabalho didático, isto é, nessas sociedades primitivas "[...] basta a formação mútua de cada um por todos, que há de ser completada pela iniciação dispensada do xamã [...]" (IDEM, p. 274, grifos meus) para garantir esta organização didática enquanto "função" histórica e social. Mais ainda, acredita-se aqui, que ela é intencional, porém não sistematizada, pois, elegido um determinado sujeito dotado das condições necessárias para realizar e satisfazer essa necessidade da comunidade de transmitir/ensinar para as camadas jovens toda a riqueza cultural elaborada com vistas a preservar esse legado, ela torna-se intencional.

Entretanto, essa intencionalidade, entende-se aqui como "não sistematizada" visto que ela poderia ocorrer no bosque, ao redor de uma fogueira, durante um rito de passagem, durante a coleta ou mesmo na caça. (CAMBI, 1999; ENGELS, 2010; GUSDORF, 1970; HAVELOCK, s/d; 1996; LARROYO, 1974; MARX, 1986; PONCE, 2007; VYGOTSKY; LURIA, 1996)

É nesse sentido que, aqui se contrapõe ao entendimento de que, o "processo educativo de forma intencional" deu-se somente após o surgimento da escrita como propõe Gusdorf (1970, p. 270, grifos nossos):

\begin{abstract}
Eis porque a invenção da escrita corresponde ao advento de um novo tipo de mestre. $O$ ensino muda de caráter, ou melhor, a função docente propriamente dita faz o seu aparecimento [...] Na Idade da Escrita, a sabedoria difunde mitos tradicionais, cede o lugar a um saber [...] A função docente, assim aparecida no momento em que a cultura falada cede lugar a uma cultura escrita corresponde a uma mudança de escala no saber como na existência social [...]
\end{abstract}

Embora, sua constatação seja de uma veracidade e de grande coerência, o que o presente trabalho busca apresentar é que, mesmo em um Modo de Produção Primitivo, houve formas históricas de educadores, de educandos, uma forma histórica de relação educativa, com um instrumental mediador e em locais específicos (como no caso dos momentos de rituais de passagem). E que, toda essa "organização" de trabalho didático, dava-se de forma "intencional", porém, não sistematizada.

Entretanto, para assim categoriza-la, enquanto organização do trabalho didático, é necessário levar-se em consideração o fato de que, esta categoria analítica no plano mais genérico, primeiramente, deve-se captar os condicionantes materiais do contexto histórico da sociedade/civilização objeto de análise, neste caso um Modo de Produção Primitivo com contextos históricos singulares. (ALVES, 2005; 2006; ENGELS, 2010; MARX, 1995; 1987) Posteriormente, identificar o "tipo histórico de relação educativa", neste caso, tem-se que 
essa relação educativa "completada" por um tipo histórico específico de educador determinado, que aqui designamos por "ágrafo bardo". Por se tratar de um "sujeito específico" responsável por levar a cabo esse tipo histórico de educação, ela é, portanto, "uma espécie primitiva de preceptorado", isto é, o gérmen, embrião, gênese do processo de preceptorado produzido e que atingiu seu apogeu na Idade Média/Período Feudal.

A partir da constatação acima enunciada, instaura-se a problemática relativa ao "instrumental didático mediador". Neste contexto estudado, chegou-se a um impasse, teórico-metodológico, visto que, a partir da perspectiva adotada de análise, identificação, estudo e reflexão, constatou-se que a "linguagem oral" "fala ritmada" foi o produto elaborado pelo homem primitivo como instrumento cultural catalisador e mediador dessa primeira forma histórica de relação educativa.

Isto é, o "instrumental mediador" não se caracterizava enquanto uma "técnica desenvolvida materialmente a partir dos recursos naturais encontrados na própria natureza enquanto resultado dialético da relação de domínio do homem sobre a natureza", este "instrumental didático" nestas sociedades, acredita-se estar limitado apenas "a fala, a linguagem" que nas formas transicionais de desenvolvimento destas formações socioculturais primitivas, não haviam ainda desenvolvido a "técnica da escrita primitiva" como é o caso dos "desenhos pictográficos". (HAVELOCK, 1996; VYGOTSKY \& LURIA, 1996)

Estabelecida uma relação educativa, historicamente condicionada ao seu contexto, o terceiro aspecto do "tripé" no qual se organiza o trabalho didático, a saber, o "local específico", concretamente, como insinuado anteriormente, ocorria nas mais variadas situações do cotidiano dos ofícios realizados no interior da comunidade. Ela se dava desde um simples passeio às florestas e bosques, ou no momento de caça, ou pesca, ou durante o plantio e coleta dos produtos cultivados como também, poderia ser realizada de forma mais elaborada durante os rituais de iniciação, por exemplo. (ALVES, 2005; 2006; ENGELS, 2010; GUSDORF, 1970; HAVELOCK, s/d; 1996; LARROYO, 1974; MARX, 1986; MARX \& ENGELS, 2005; PONCE, 2007; RIBEIRO, 1985; VYGOTSKY; LURIA, 1996)

Apresentada elementos com os quais, acredita-se coadunarem com as dimensões constitutivas, conceitualmente, da categoria analítica Organização do Trabalho Didático no Modo de Produção Primitivo, e a partir dessa análise e reflexão, identificados um tipo histórico de educador, que aqui, optou-se por designá-lo por "ágrafo bardo", apresenta-se a seguir, a justificativa que consubstancia a escolha desta determinada terminologia para categorizar esta primeira forma histórica de educador, responsável pelo trabalho didático no Modo de Produção Primitivo.

\section{Por que a primeira forma histórica de educador a realizar um trabalho didático fora um ágrafo-bardo?}

Neste sentido, considerou-se difícil e perigoso estabelecer uma nomenclatura padrão para designar esses indivíduos. No entanto, há algumas denominações, vinculadas nos manuais investigados, remetendo-se a estes períodos finais dos "estágios comunal, tribal, selvagens e de barbárie” (BEER, 2006; ENGELS, 1987; RIBEIRO, 1985), a saber: "ágrafos, Aedo, bardos, recitadores, poetas, xamãs, gurus, sábios, feiticeiros, preceptores, anciões, etc." (CAMBI, 1999; ENGELS, 2010; GUSDORF, 1970; HAVELOCK, s/d; 1996; LARROYO, 1974; LUZURIAGA, 1990; PONCE, 2007). Obviamente que, cada uma dessas 
nomenclaturas tem uma razão de ser e um contexto específico, o que torna receoso utilizar uma em detrimento de outra. Mesmo assim, dado às circunstâncias em que este trabalho de investigação desenvolveu-se, optou-se por utilizar uma terminologia específica para designar esse grupo de indivíduos, a saber: "ágrafo-bardo".

Primeiramente, escolheu-se esta designação pelo fato de ser utilizada (ou ao menos insinuada) pela maioria dos autores selecionados para este estudo, ora utilizando à primeira, ora a segunda. Portanto, tem-se a clareza de que tal designação, não se trata de uma falácia assim como também não se trata de uma unanimidade entre os estudiosos de outras as áreas científicas especializadas que os tomam por objeto de estudo. Em segundo, partindo do pressuposto e do estudo histórico empreendido até o presente momento o qual, iniciou-se a partir das "sociedades sem escrita" ou nos dizeres de Havelock (s/d; 1996) "sociedades oralizadas" neste período primevo (BEER, 2006; ENGELS, 1987; ENGELS, 1985; 2005; RIBEIRO, 1985), percebeu-se, portanto, como se destacou acima, que a relação educativa entre esses "educadores" e as jovens camadas, "era mediada pela linguagem". Ou seja, utilizavam como mecanismo de enculturação/aculturação (MANACORDA, 2007) um tipo fala/linguagem essencialmente ritmada, logo, designá-los por "bardos", devido a sua função, considerou-se coerente.

Do mesmo modo, considerou-se pertinente utilizar a designação de "ágrafo" para estes grupos (e os demais membros da comunidade, obviamente) pelo fato de que, não possuíam uma técnica de escrita "ideográfica, linear e/ou alfabética". (HAVELOCK, s/d; 1996) O que se pode constatar, é a existência da chamada "escrita pictográfica em forma de pinturas rupestres", técnica esta a qual, perdurou por milênios e que serviu de base para o desenvolvimento das escritas nos povos egípcios e mesopotâmicos, principalmente nesta última com a comunidade fenícia a qual, segundo Havelock (1996) proporcionou as bases para o desenvolvimento do alfabeto grego, porém tal estudo excede os limites das proposições as quais este trabalho tenta empreender. Portanto, em uma comunidade sem escrita (iletrada, oralizada) tribal, não utilizar a terminologia "ágrafo" nos parece ser um tanto inapropriada ainda que tal argumentação e perspectiva possam transparecer uma "visão de explorador conquistador".

Não obstante, Ponce (2007, p. 27, grifos nossos) argumenta e corrobora com as considerações acima, sustentando a ideia de que:

\footnotetext{
Cada tribo foi recolhendo através dos anos uma larga experiência que foi sendo cristalizada em tradições e mitos. Mescla caótica de saber autêntico e de superstições religiosas, esse acervo cultural constituía o reservatório espiritual que protegia o grupo [...]
}

Percebe-se ainda que, muito rudimentarmente, essas comunidades explicitam sinais de grande desenvolvimento quanto aos processos e procedimentos educativos espontâneos, naturais e não sistematizados as quais irão, doravante, cristalizar-se de forma sistemática e organizada, uma educação bem diferente daquela homogênea e espontânea que até aquele momento era vigente (PONCE, 2007, p. 27), o que exigiu consequentemente, um desenvolvimento mais elevado das qualidades, habilidades e capacidades dos indivíduos incumbidos de promoverem a "educação" destes jovens. Pois, além das habilidades da fala e da bagagem cultural interiorizada, deveria ser de um ponto de vista subjetivo, indivíduos com virtudes morais e intelectuais destacadas de tal modo que no interior da comunidade lhe atribuíssem tal status quo e função social (DOZOL, 2003).

Portanto, em tais comunidades, apresentavam-se como sujeitos responsáveis pelos mecanismos de transmissão-enculturação, os "ágrafos bardos", estes a partir da produção de 
mediações didáticas específicas, tais como: recitação ritmada, invocações cantaroladas, formas de fala rítmica cantadas, etc. Assim, estes sujeitos "protointelectuais" nas palavras de Havelock (1996, p. 19), "protoartesões" nas de Cambi (1999, p. 57), no usufruto de tais mecanismos, exercitavam, cotidianamente ou em ocasiões específicas como os cerimoniais de iniciação (por isso, alguns autores os denominam como xamãs), suas capacidades orais e mnemônicas e assim, iam paulatina e gradativamente desenvolvendo os processos educativos ainda que de forma rudimentar e não sistematizadas.

Quanto ao processo de desenvolvimento desta forma de fala (ou linguagem) considerou-se aqui como um estágio intermediário de aquisição da linguagem articulada (VYGOTSKY; LURIA, 1996). Por sua vez, após alguns séculos, senão milênios, de experiência, de interação, fabricação de instrumentos diversos, organização social complexa, uma cultura específica (hábitos, costumes, crenças) e um refinamento (lento, mas gradativo) de uma fala ritmada para uma fala articulada, é que se pode vislumbrar o surgimento destes grupos de educadores e com eles a preservação e acúmulo cultural produzido mediante a interação com a natureza e seus condicionantes. (HAVELOCK, S/D; 1996; VYGOTSKY; LURIA, 1996)

Por fim, acredita-se que nas comunidades primitivas tribais (iletradas) a forma histórica de relação educativa deu-se já em caráter de "preceptorado"; sendo a primeira forma desenvolvida de educador, o que designamos de "ágrafo-bardo"; quanto ao instrumental mediador desta relação, houve uma variedade, pois, cada tempo e lugar, produziram o instrumento em acordo com os condicionantes materiais ao seu tempo, no caso dos ágrafos-bardos, chegou-se a uma questão bastante peculiar e interessante, qual seja, acredita-se ter sido a "linguagem ritmada" o primeiro instrumental didático. Quanto ao local, estes também variavam de acordo com o contexto, como já dito anteriormente, eram utilizados desde simples passeio às florestas e bosques (caça, pesca, coleta e plantio) como também os rituais de iniciação (ritos de passagem, por exemplo) no interior da comunidade. (ALVES, 2005; CAMBI, 1999; ENGELS, 2010; GUSDORF, 1970; HAVELOCK, s/d; 1996; LARROYO, 1974; MARX, 1986; PONCE, 2007; VYGOTSKY; LURIA, 1996)

\section{Referências}

ALVES, Gilberto Luiz. O Trabalho Didático na Escola Moderna: formas históricas. Campinas, SP: Autores Associados. 2005. . A Produção da Escola Moderna Contemporânea. $4^{\mathrm{a}}$ ed. Campinas, SP:

Autores Associados, 2006.

ANTUNES, Ricardo (Org.) - A Dialética do Trabalho. Escritos de Marx e Engels. São Paulo: Expressão Popular, 2004.

ARANHA, Maria Luiza de Arruda. História da Educação e da Pedagogia: Geral e Brasil,

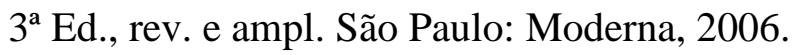

BOTTOMORE, Tom (Org.) Dicionário do Pensamento Marxista. Editor: Laurence Harris, V. G. Kiernan, Ralph Miliband, co-editores; [tradução, Waltensir Dutra; organizador da edição brasileira, revisão técnica e pesquisa bibliográfica suplementar, Antonio Moreira Guimarães]. - Rio de Janeiro: Jorge Zahar ED., 2001.

BEER, Max. História do Socialismo e das lutas de classes. Trad. Horácio de Melo. $1^{\text {a }}$ Ed. São Paulo: Expressão Popular, 2006. 
CAÇÃO, Maria Izaura - Jornada de Trabalho Docente: delineamento histórico da organização do trabalho do magistério público estadual paulista. (Tese de doutorado em Educação). Faculdade de Educação, Universidade Estadual de Campinas. Campinas: 2001.

CAMBI, Franco. História da Pedagogia. São Paulo: Ed. UNESP, 1999.

DIAKOV, V. \& KOVALEV, S. - História da Antiguidade: A sociedade Primitiva e o Oriente. Ed. Global: 1987. Disponível em: http://opiniaosocialista.wordpress.com/textosfundamentais/a-sociedade-primitiva. Acessado em: 04/junho/2011.

DOZOL, Marlene de Souza. Da Figura do Mestre. Campinas, SP: Autores Associados: São Paulo: Editora da Universidade de São Paulo. 2003.

ENGELS, Friedrich. A Origem da Família, da Propriedade Privada e do Estado: trabalho relacionado com as investigações de L. H. Morgan. $11^{\mathrm{a}} \mathrm{ed}$. Trad. Leandro Konder. Civilização Brasileira. 2010.

O papel do trabalho na transformação do macaco em homem. Escrito por Engels em 1876. Publicado pela primeira vez em 1896 em Neue Zeit. Publica-se segundo a edição soviética de 1952, de acordo com o manuscrito, em alemão. Traduzido do espanhol. Disponível em: http://www.histedbr.fae.unicamp.br/acer_fontes/tme_09.pdf. Acessado em: 05/06/2011.

FERNANDES, Hélio Clemente. O Trabalho Docente: pauperização, precarização e proletarização? Dissertação (Mestrado em Educação) - Universidade Estadual do Oeste do Paraná. Campus de Cascavel. 2010.

GIL, Antonio Carlos. Métodos e Técnicas em Pesquisa Social. $6^{\mathrm{a}}$ Ed. $2^{\mathrm{a}}$. Reimpr. SP: Ed. Atlas, 2009.

GIORDANI, Mario Curtiz. História da Antiguidade Oriental. $3^{\mathrm{a}}$ ed. Vozes, Petrópolis, RJ, 1972.

GUSDORF, Georges. Professores para quê? Para uma pedagogia da pedagogia. Trad. João Bernard da Costa e Antônio Ramos Rosa. $2^{\mathrm{a}}$ ed. Moraes editora. 1970.

HAVELOCK, Eric. A revolução da escrita na Grécia e suas consequências culturais. Trad. Ordep José Serra. São Paulo: Editora da Universidade Estadual Paulista. Rio de janeiro: Paz e Terra, 1996.

A educação numa Sociedade sem Escrita. In: VIAL, Jean \&MIALARET, Gaston (Org.) História Mundial da Educação, 1. ${ }^{\circ}$ vol., Porto, Rés-editora, s.d.

HOBSBAWN, Eric. Prefácio IN: MARX, Karl. Formações Econômicas Pré-Capitalistas. Trad. João Maia, Revisão Alexandre Addor. $5^{\text {a }}$ ed. Paz e Terra. 1986.

KUENZER, Acácia. Exclusão includente e inclusão excludente: a nova forma de dualidade estrutural que objetiva as novas relações entre educação e trabalho. In: LOMBARDI, J. C.; SAVIANI, dermeval \& SANFELICE, José Luiz (Org.) - Capitalismo, Trabalho e Educação. $3^{\text {a }}$ Ed. Campinas -SP: Autores Associados, Histedbr, 2005.

LANCILlOTI, Samira Saad Pulchério. A Constituição Histórica do Processo de Trabalho Docente. Unicamp-SP. Campinas, SP: [s. n.], (Orientador: Jose Luiz Sanfelice, tese de doutorado- Universidade Estadual de Campinas, Faculdade de Educação), 2008.

LARROYO, Francisco. História Geral da Pedagogia. Trad. de Luiz Aparecido Caruso; rev. de Selma Cury; 12a Ed. SP; Tomo I; Ed. Mestre Jou; 1974. 
LEACOCK, Eleanor Burke. Posfácio: Introdução à edição estadunidense. IN: A Origem da Família, da Propriedade Privada e do Estado: trabalho relacionado com as investigações de L. H. Morgan. $11^{a}$ ed. Trad. Leandro Konder. Expressão Popular. 2010.

LIBÂNEO, JOSÉ Carlos. Pedagogia e pedagogos, para quê? Ed. Cortez. 1998.

LUDKE, Menga \& BOING, Luiz Alberto. Caminhos da profissão e da profissionalidade docentes. Educ. Soc., Campinas, v. 25, no 89, dez. 2004. Disponível em:

http://www.scielo.br/scielo.php?script=sci_arttext\&pid=S0101-

73302004000400005\&lng=pt\&nrm=iso. Acessos em 08 jul. 2011.

LUZURIAGA, Lorenzo. História da Educação e da Pedagogia. Tradução de Luiz Damasco Penna e J. B. Damasco Penna; $18^{a}$ ed. SP; Ed. Nacional, vol. 59; 1990.

MANACORDA, Mario Alighiero. História da Educação: da Antiguidade aos nossos dias. 8ed. São Paulo: Cortez, 2007.

MARROU, Henri Irenee. História da Educação na Antiguidade. Trad. Mário Leônidas Casanova. SP: EPU, Brasília, INL, 4ª reimpressão, 1975.

MARX, Karl. Formações Econômicas Pré-Capitalistas. Trad. João Maia, Revisão Alexandre Addor. $5^{\text {a }}$ ed. Paz e Terra. 1986.

Contribuição à Crítica da Economia Política. $2^{\mathrm{a}}$ ed. São Paulo: expressão

Popular. Trad. e Intr. de Florestan Fernandes. 2008.

; ENGELS, Friedrich. A Ideologia Alemã. Feuerbauch - A oposição entre as concepções materialista e idealista. Trad. Frank Muller. $3^{\mathrm{a}}$ ed. Martins Claret, 2005.

MIALARET, Gaston \& VIAL, Jean - História Mundial da Educação, 1. ${ }^{\circ}$ vol., Porto, Réseditora, s.d.

MONROE, Paul. História da Educação. Nova tradução e notas de Idel Becker. $11^{\mathrm{a}}$ Ed. SP. Ed. Nacional, 1976.

PERRENOUD, Philip. dez Novas Competências para Ensinar. Porto Alegre, Artmed, 2000.

PIMENTA, Selma Garrido \& GHEDIN, Evandro (Org.) - O Professor Reflexivo no Brasil: gênese e critica de um conceito. SP: Cortez, 2008.

PONCE, Aníbal. Educação e Lutas de Classe. Trad. José Severo de Camargo Pereira. 22a ed. São Paulo: Cortez, 2007.

RIBEIRO, Darcy. O Processo Civilizatório: estudos antropológicos; etapas da evolução sociocultural. 9a ed. Petrópolis; Vozes, 1987.

SANTONI RUGIU, Antonio. Nostalgia do Mestre Artesão. Trad. Maria de Lourdes Menon. Campinas-SP: Autores Associados, 1998.

SAVIANI, dermeval. A Função Docente e a Produção do Conhecimento. V. 11 n. 21. p. 127-140, jan/jun e jul/dez, 1997. Rev. Educação e Filosofia. Disponível em:

http://www.seer.ufu.br/index.php/EducacaoFilosofia/article/view/889/806. Acessado em: 24/Junho/2011.

Prefácio. IN: Nostalgia do Mestre Artesão. trad. Maria de Lourdes Menon. Campinas-SP: Autores Associados, 1998.

. História das Ideias Pedagógicas no Brasil. $2^{\mathrm{a}}$ Ed. rev. e ampl. Campinas-SP:

Autores Associados, 2008. 
VEIGA, Ilma Passo Alencastro; ARAUJO, José Carlos Souza \& KAPUZINIAK, Celia (Org.) - Docência: uma construção ético-profissional. Ed. Papirus. 2005.

\& D’ÁVILA, Cristina Maria (Org.) - Profissão Docente: novos sentidos, novas perspectivas Ed. Papirus. 2008.

VYGOTSKY, Lev Semenovich \& LURIA, Alexander Romanovich. Estudos sobre a História do Comportamento: o macaco, o primitivo e a criança. Trad. Lólio Lourenço de Oliveira. Porto Alegre: Artes Médicas, 1996.

WENZEL, Renato Luiz. Professor: agente da educação? Campinas, São Paulo: Papirus, 1994.

Notas

${ }^{1} \mathrm{PMCB}$

Graduado em Pedagogia - Licenciatura Plena (diurno) na Universidade Federal de Santa Maria - UFSM (2011). Pós-graduando em Tecnologias da Informação e Comunicação na Educação TICEDU pela Universidade Federal de Rio Grande- FURG. Atualmente é professor de educação infantil concursado no Município de Campo Bom-RS e realiza estudos e pesquisas na área de Educação, com ênfase em: Organização do Trabalho Didático, Educação Infantil e Educação, Sociedade e Trabalho. Email: martinsjander@yahoo.com.br

2 Aqui se optou por utilizar as três designações separadas por "barra", pelo fato de se acreditar que cada uma delas, além de seu sentido semântico, carrega também um sentido diferente ao serem empregadas para designar o "ato de docência" dependendo do contexto histórico e época. Isto é, ao se pensar nas diferentes formas históricas de educador, pensa-se que "ofício" torna-se mais coerente para representar os "educadores da Idade Média", visto que, este ofício conota melhor este ato que era eminentemente realizado por grupos sacerdotais ligados à Instituições Religiosas (MARROU, 1974). No entanto, com o advento do Modo de Produção Capitalista, pensa-se que este "ato" que deixa de ser essencialmente realizado por grupos religiosos, embora haja uma predominância dos Jesuítas, passa-se a ser laico e condiciona-se a um processo de profissionalização "remunerada", o que, em nosso em entendimento, caracteriza-se como um ato de "trabalho imaterial" (MARX in ANTUNES, 2006) que é produtivo ou não produtivo de acordo com o tipo de relação que se estabelecia entre o educador e o seu chefe, no caso do ensino privado/particular, (IDEM). Assim, ora será utilizado à terminologia "relação educativa", quando há o ato espontâneo e não-intencional entre um indivíduo que através de canções, rituais, danças transmite todo o legado cultural de sua comunidade para os demais jovens. E "ofício" quando este passa a ter um caráter "intencional sistematizado ou não" de ensino. E "trabalho" quando se referir ao contexto já pedagógico, sistematizado, organizado e condicionado aos ditames do processo de valorização da força de trabalho (física e mental) com um fim específico, no caso da Idade Moderna, por exemplo, de ensinar tudo a todos como Comenius preconizava em sua Didática Magma.

${ }^{3}$ Segundo Alves (2005, p. 10-11, grifos do autor) "No plano mais genérico e abstrato, qualquer forma histórica de organização do trabalho didático envolve, sistematicamente, três aspectos: a) ela é, sempre, uma relação educativa que coloca, frente a frente, uma forma histórica de educador, de um lado, e uma forma histórica de educando(s), de outro; b) realiza-se com a mediação de recursos didáticos, envolvendo os procedimentos técnico-pedagógicos do educador, as tecnologias educacionais pertinentes e os conteúdos programados para servir ao processo de transmissão do conhecimento; c) e implica um espaço físico com características peculiares, onde ocorre".

${ }^{4}$ Como argumenta Alves (2005, p. 3, grifos nossos), mesmo sendo discutível esta terminologia conferida por Marx e Engels (2005), "principalmente por ter sido suprimida quando da revisão do texto de A Ideologia Alemã, ainda é preferível [...]". Assim sendo, entende-se por Ciência da História, "a radical revelação da historicidade das obras humanas, inclusive da própria concepção que a preside, bem como da forma de produzir conhecimento que lhe é pertinente". Complementando tal acepção, Lancillotti (2008, p. 1, grifos nossos) assim acrescenta: "a despeito de ter sido suprimida na versão final do manuscrito, esta nota explicita a adesão radical dos autores ao entendimento de que todas as obras humanas são históricas, um princípio que deve iluminar toda análise social". 


\begin{abstract}
${ }^{5}$ Se partiu do entendimento que Leacock (2010, pp. 231-234) discorre em seu Posfácio na obra de F. Engels $A$ Origem da Família, da propriedade Privada e do Estado, 2a edição, 2010 da editora Expressão Popular. Nesta obra, a autora, se refere a esta categoria, como uma questão imprescindível ao se tratar de questões como as que se referem às diferentes formas de organização social, e que aqui merece ser discorrida, resumidamente. Para a autora, esta "categorização de níveis sucessivos" é um pressuposto encontrado recorrentemente nas ciências naturais. Entretanto, a autora assim se manifesta: "Há um fracasso comum em distinguir a definição de está gios como um passo preliminar necessário para colocar questões significativas sobre um determinado período, instituição ou evento, e os estágios vistos como sendo eles mesmos as respostas. "Estágios" definem as principais alternativas na estrutura das relações produtivas; eles fornecem um marco conceitual para o estudo do processo histórico. Colocar uma sociedade numa posição central ou transicional em relação a um ou mais estágios é um passo preliminar necessário para a indagação, e não uma camisa de força que a limita." (2010, p. 234, grifos nossos). Portanto, como a própria autora neste fragmento argumenta estabelecer determinadas margens trata-se de um mecanismo que, parafraseando Morgan Apud Leacock (IDEM, p. 232), é "conveniente e útil, mas provisório".
\end{abstract}

${ }^{6}$ Em sua "fase inferior", é tratado pelo autor, como sendo "a infância do gênero humano", o qual vivia em pequenos bandos e residia quase que exclusivamente nos bosques e florestas, sua alimentação era constituída de frutos e raízes (ENGELS, 2010, pp. 37-38). Além disso, segundo o autor "nenhum dos povos conhecidos pertenceram a este período" (idem.), entendimento este, fundamentado no seu outro manuscrito supracitado. Portanto, tratava-se de um modo de vida organizado em pequenos bandos e que se assentava sobre um processo de realização das necessidades imediatas básicas, viviam apenas de um "modo de vida horticultor", predominantemente. Quanto a sua "fase média", este período, tradicionalmente, é compreendido como o "Paleolítico", visto que, o modo de subsistência modifica-se devido a "dois (2) fenômenos complementares", ou seja, o "emprego do peixe e com o uso do fogo". Além de uma nova alimentação, iniciam-se também as primeiras produções de "instrumentos de pedra sem polimento da primitiva Idade da Pedra" (ENGELS, 2010, p. 38). Além disso, para o autor, os "povos" desta época eram ainda em sua maioria, "horticultores e coletores", em sua dieta alimentar, com o fogo, "levaram ao emprego de novos alimentos, como raízes e os tubérculos farináceos cozidos em cinza quente" (idem). Por fim, em sua "fase superior", segundo o autor, "começa com a invenção do arco e flecha", fenômeno este, o qual proporcionará uma nova condição de subsistência, pois, com isso, introduz-se a "carne" em sua dieta alimentar. Tal produção foi tão importante que Engels assim pondera: "o arco e a flecha foram, para a época selvagem, o que a espada de ferro foi para a barbárie e a arma de fogo para a civilização: a arma decisiva" (ENGELS, 2010, p. 39).

${ }^{7}$ No entanto, esta antiga concepção de que a "história é linear", há algum tempo deixou de ser um pensamento corrente na História (inclusive na história da educação). Ao contrário, pensa-se e afirmam-se hoje, que, a história é dinâmica, dialética, cheia de embates, de rupturas, de reorganizações através de movimentos de contradições, saltos qualitativos, de unidade e identidade de contrários, da negação da negação, que é produzida pelo próprio homem em sua relação de domínio da natureza e entre eles próprios. (ALVES, 2005; BEER, 2006; CAMBI, 1999; ENGELS, 2004; 2010; HOBSBAWM, 1986; LARROYO, 1974; MANACORDA, 2000; MARX, 1986; MARX \& ENGELS, 2005; RIBEIRO, 1985; PONCE, 2007).

${ }^{8}$ O sentido dado a este termo no presente estudo leva em consideração a relação concreta ocorrida histórica e culturalmente neste tipo específico de Modo de Produção Primitivo a qual colocava de um lado "um sujeito educador/que ensina algo" e do outro, "um sujeito jovem que aprende e se apropria da totalidade de riqueza produzida no interior da comunidade". Esta relação de preceptoria, então, acredita-se se aproximar do sentido dado por MARROU (1975) ao termo "preceptor coletivo", evidentemente, que levado em consideração ao fato de que, aqui se trata de um contexto histórico primitivo e ao que esse autor cita ao Escravagista Grego o qual era materializado pelo "Sofista" essa relação de preceptoria ora individual ora coletiva. Pois, como se tentou acima evidenciar, embora todos os autores que nos serviram de objeto de análise partam do mesmo ponto comum, isto é, que a "educação primitiva não era sistematizada, "não intencional' e era em caráter coletivo" tentou-se promover uma reflexão sobre a possibilidade desta relação educativa, a partir do viés conceitual acima esposado, ocorrer em "caráter de preceptorado ora individualizado e/ou ora coletivo", no sentido proposto por MARROU (IDEM), e de forma “intencional” embora não sistematizada.

Recebido: janeiro/13 Aprovado: julho/13 